（132）道路橋の免震装置の等洒線形化手法と

特性値の設定方法について

\begin{tabular}{|c|c|c|c|c|}
\hline 俌奥村組 & ○高橋 & 一成 & 大戊建設侎 & 尾酠 \\
\hline 成間組 & 忪原 & 勝巨 & 西忪建設㑣) & 高木 \\
\hline ノス工咩㑣) & 牧口 & 豊 & 㥻ブリヂストン & 水津 \\
\hline
\end{tabular}

\title{
1. 亲光が过
}

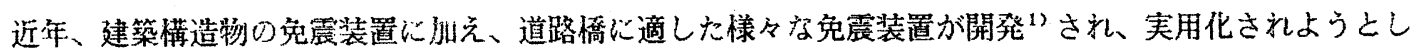
ている。これら免震装置の復元乃特性の多くは非線形性を示少が、免震憍梁の設䚺以おいては設計の便を考

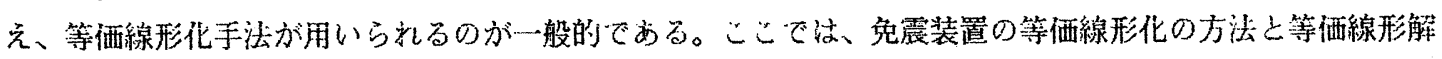

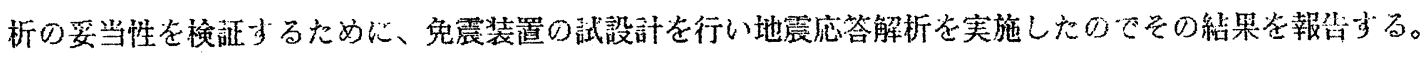

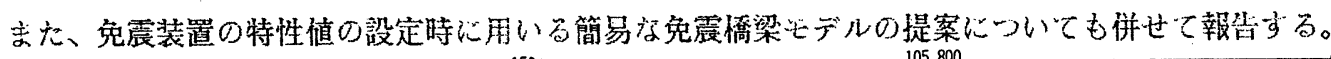

\section{2. 免震装置の試設計}

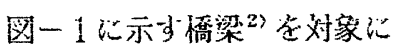
免震装置它试設計した。免震装 置の櫣造設計性「道路橋の免震 設計法ガイトライン(案)」きを 参考心行い、いずれも地震時保

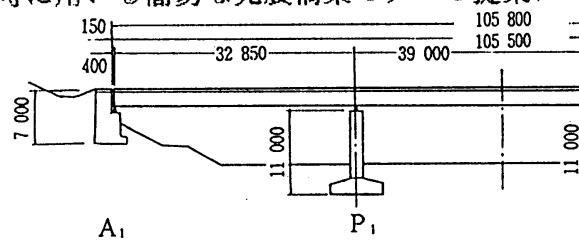

Fig. -1 General View of Three Span Bridge

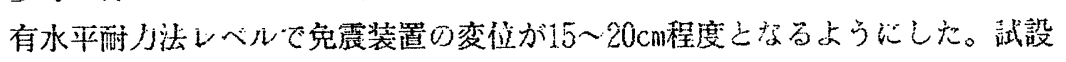

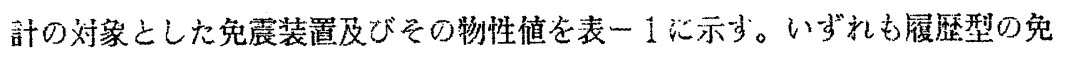

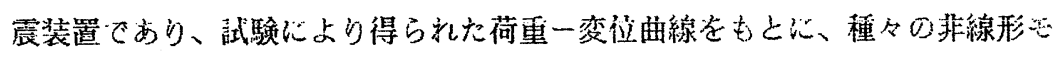
デルでデル化される。スパイラル鋼棒多ンパーのモデル化の例学图一 2 に示

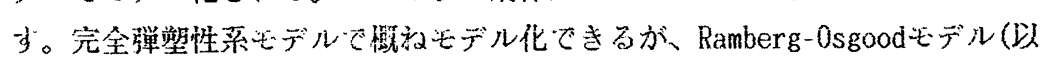

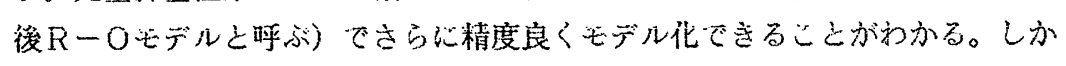

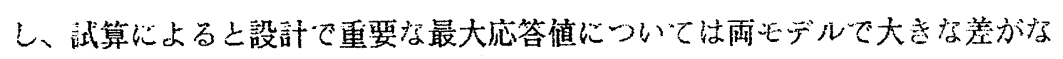
く (図ー7参照)、設計に用いる実用的な韭線形モデルとして、積層ざムの線

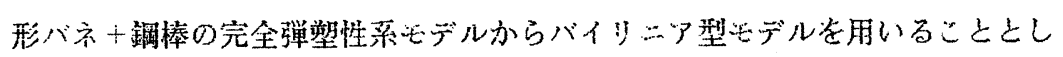
た。表一1以示した他の装置でも同様の絬果が得られ、ここでは非線形モデル としてパイリニア型モデルを用いることにした。

\section{3. 免震装置の等価楾形化手法}

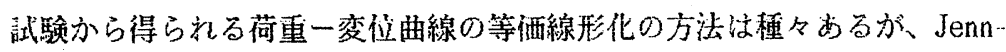
ingsらにより整理 ${ }^{4}$ さ礼ている方法亦ら、ここでは奖の 3 手法が免震装置に適

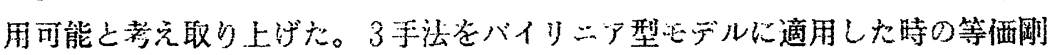

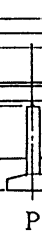

$P_{2}$

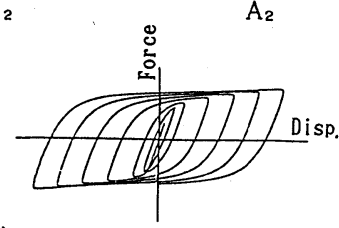

(a) Experinental Hysteresis Loops

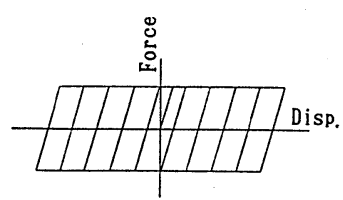

(b) Idealised Hysteres is Loops (Elasto-Plastic Model)

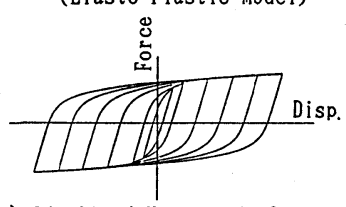

(c) Ideal ised Hysteresis Loops (Ramberg-Osgood Model)

Fig.-2 Hysteresis Loops of Spiral Bar Damper
性、等酒減衰定数の算定式を表一 2 に示少。

(1) Resonant Amplitude法(以後R.A.法已呼ふ)

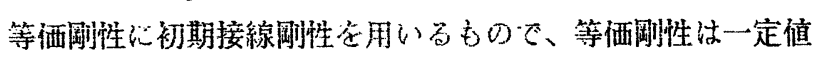
となり、等価減哀定数核他の方法化比へ小さ为の随を与光る。 計算注最も簡単である。

(2) Dynamic Stiffness法(以後D.S.法之呼ぶ)

定常状態で共振振動数、工ネルギー吸収がー致する上うに 等喓煀性、等晒減衰定数炎設定少る方法て、韭線形性を最も忠 実以評洒した方法で的るが、計算が他の方法に比べ複雑でらる。
Table-1 Properties of Menshin Devices

\begin{tabular}{|l|r|r|r|}
\hline \multicolumn{1}{|c|}{ Menshin Devices } & $Q_{v}(\mathrm{tf})$ & $\mathrm{K}_{1}(\mathrm{tf} / \mathrm{cm})$ & $\mathrm{K}_{2}(\mathrm{tf} / \mathrm{cm})$ \\
\hline Lead Rubber Bear ing & 60.0 & 123.2 & 18.9 \\
\hline High Dauping Rubber Bear ing & 61.1 & 98.0 & 19.7 \\
\hline $\begin{array}{l}\text { Rubber Bearing } \\
+ \text { Friction Danper }\end{array}$ & 64.5 & 46.4 & 16.9 \\
\hline $\begin{array}{l}\text { Elasto Sliding Bearing } \\
+ \text { Horizontal Spring }\end{array}$ & 49.0 & 81.7 & 16.9 \\
\hline $\begin{array}{l}\text { Rubber Bearing } \\
+ \text { Stainless Steel Ring Damper }\end{array}$ & 68.2 & 32.0 & 10.8 \\
\hline $\begin{array}{c}\text { Rubber Bearing } \\
+ \text { Spiral Bar Danper }\end{array}$ & 75.9 & 70.3 & 15.3 \\
\hline
\end{tabular}


(3) Geometrical Stiffness法( 以捘G.S.法之㭔心)

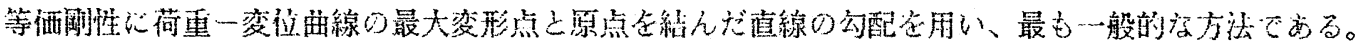

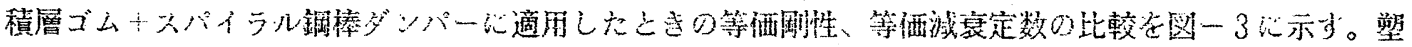

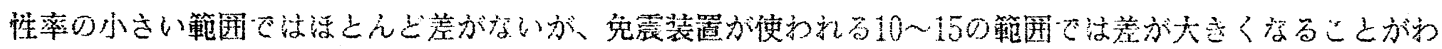
かる。

\section{4. 解析策件}

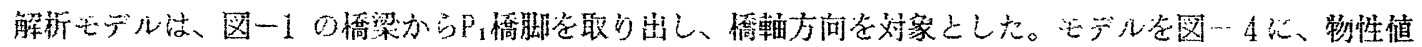

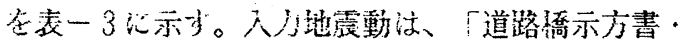

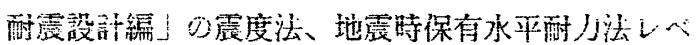
ル(以後、レベル1、レベル2己呼引)の入〉等考え

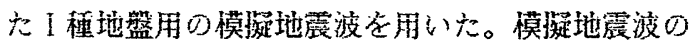

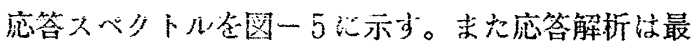
大応答值安有勃振輻とし、免震装置部の応答変往が 做定值之一致方るまで繰り返し計算を行った。

5. 店答結果の比較

(1) 最大流答徝

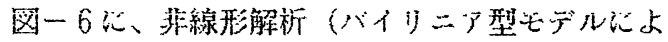
る解析) と等価線形解析 (R.A.法、D.S.法、G.S.法 による解析)の最大応答值の比較を示す。レベル1 の応答解析では、いずね等価線形解析の值も大き

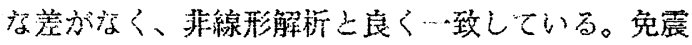
装置部の応答変位が小さ值 (塑性率が1〜5程度) ヘ西った為、各手法の周期特性の違い心伴う外少の Table-2 Equivalent Stiffness and Damping Constant

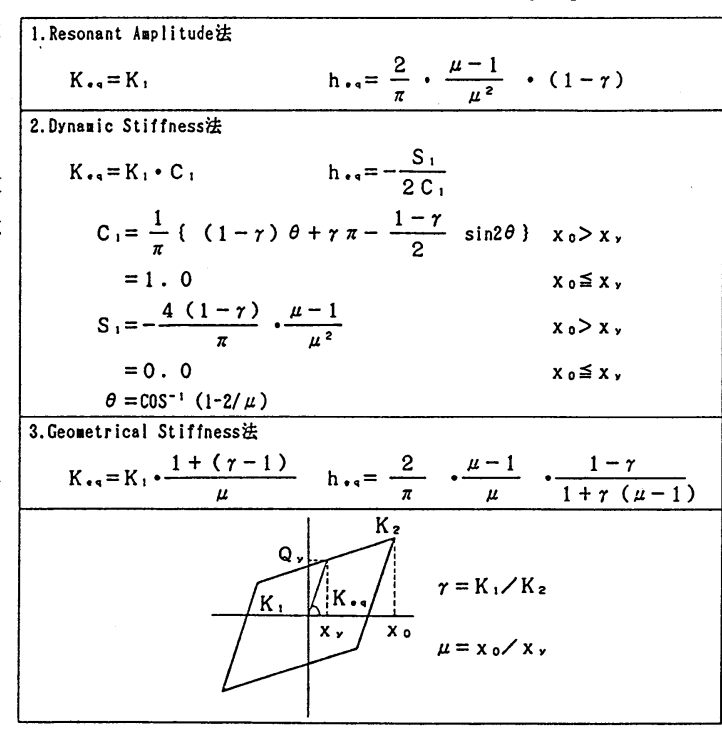

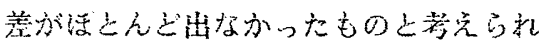
る。レベル2す茫答解析で注、1.S.法之

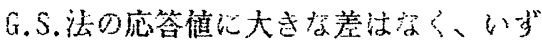
剠の応答值も非線形解析絰果之良い精度 で致していることがわかる。R.A.法は 最大杣速度、最大单げモーメント、也九

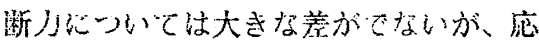
答変位に関しては、菲線形解析の1/2程 度の值宗している。これは、等価䦌性 として初期岡栍の一 定檤企用いているた め、芯答変位が大

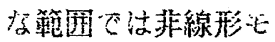
デルの周期特性之の 差公大事くなった口 ので放り、R.A.法の 適用範园定越光てい ること意濑してい ま。

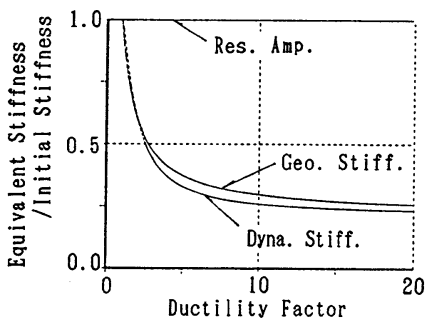

(a) Equivalent St iffness

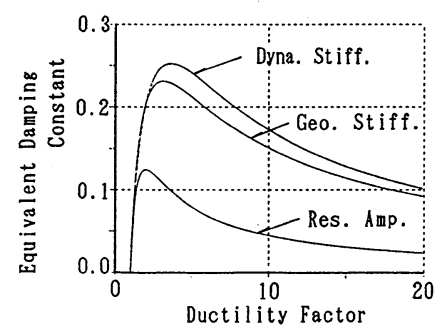

(b) Equivalent Damping Constant

Fig. -3 Ductility Factor vs. Equivalent Stiffness and Damping Constant

Table-3 Properties of Analytical Model

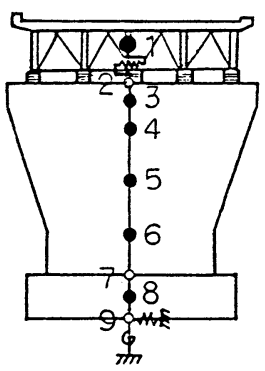

Fig. -4 Analytical Model

\begin{tabular}{|l|l|l|c|}
\multicolumn{4}{c}{ Analytical Model } \\
\hline \multirow{2}{*}{ Node No. } & \multicolumn{2}{|c|}{ E I $\left(\mathrm{t} \cdot \mathrm{m}^{2}\right)$} \\
\cline { 3 - 4 } & Level-1 & Level-2 \\
\hline 1 & 2 & & \\
\hline 2 & 3 & $1.423 \times 10^{7}$ & $6.690 \times 10^{6}$ \\
\hline 3 & 4 & $1.381 \times 10^{7}$ & $6.492 \times 10^{6}$ \\
\hline 4 & 5 & $1.233 \times 10^{7}$ & $5.801 \times 10^{6}$ \\
\hline 5 & 6 & $1.023 \times 10^{7}$ & $4.810 \times 10^{6}$ \\
\hline 6 & 7 & $9.173 \times 10^{6}$ & $4.313 \times 10^{6}$ \\
\hline 7 & 8 & $\infty$ & $\infty$ \\
\hline 8 & 9 & $\infty$ & $\infty$ \\
\hline \multicolumn{3}{|l|}{ Spring } \\
Const. & \multicolumn{3}{|c|}{$\mathrm{K}_{\mathrm{H}}=2.261 \times 10^{5}(\mathrm{t} / \mathrm{m})$} \\
\hline
\end{tabular}

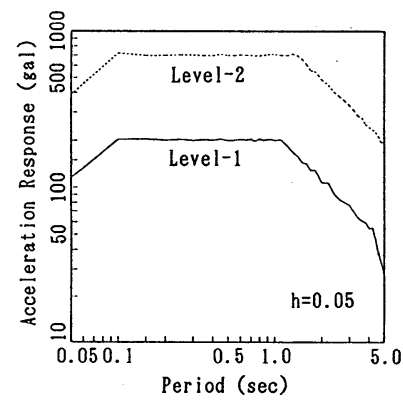

Fig. -5 Acceleration Response Spectrum 
(2) 時刻厓㞣答波形

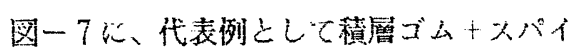

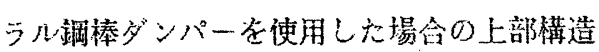

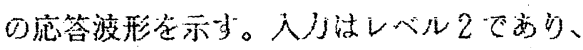

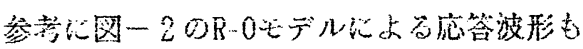

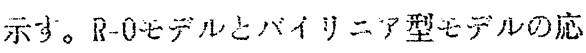

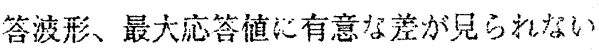

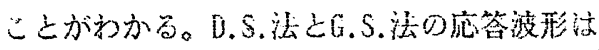

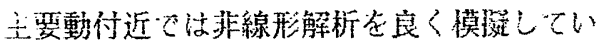

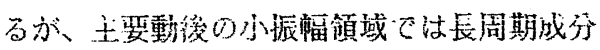
が卓越し韭線形解析之椂禁暴儿している。

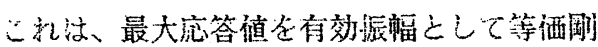

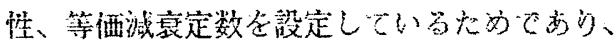

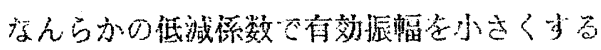

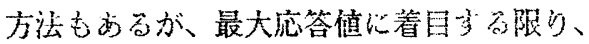
今回用いた評洒方法で十第已淁えられる。

6. 免㫳装置の特性䛧の設定方法

所要の免震效果が得られるように先震装置

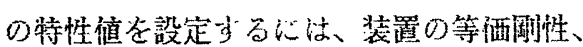

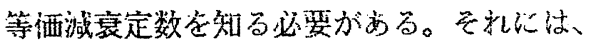

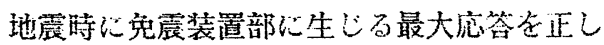

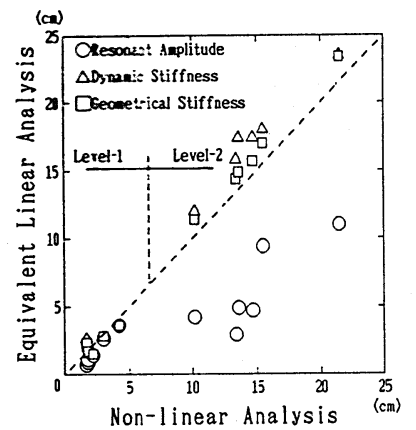

(a) Maximun Menshin Device Disp.

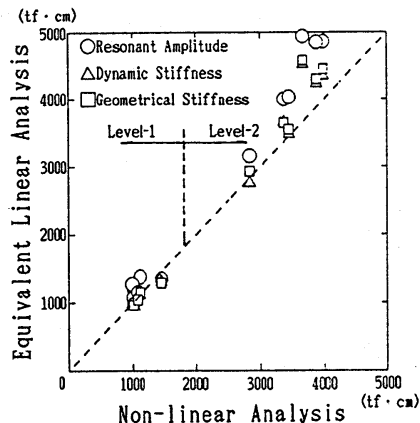

(c) Maximun Pier Bending Moment

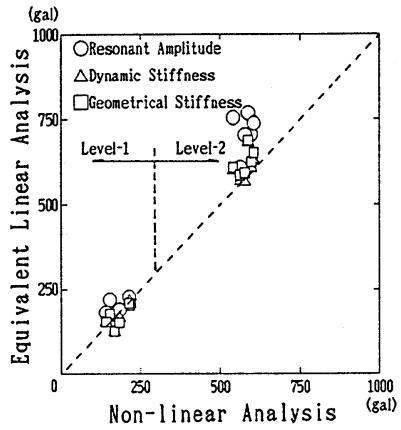

(b) Maximun Superstructure Acc.

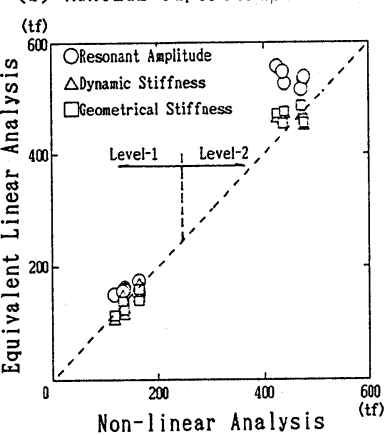

(d) Maximun Pier Base Shear
Fig. -6 Comparison between Non-linear Analysis and Equivalent Linear Analysis

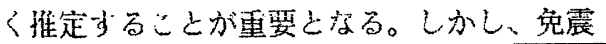
装置の愎元j特性が非線形性走示す 為、疮答徝安知る心は、(1装置部の

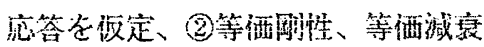

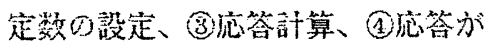

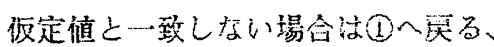
という繰り返し計算が必要亡なる。

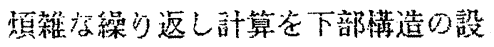

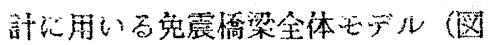

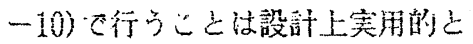

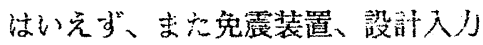
地震動、橋梁形式等定收定し、予少 訐算した于ャートも提案さ礼ている か、適用範迸が非常以限られている。 そしで、特性值の設定に用いるもデ ルさしてi）装置部の応答が精度良

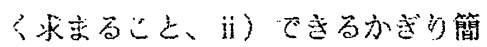

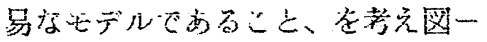

\begin{tabular}{|c|c|c|c|}
\hline & & Superstructure Displacement & Superstructure Acceleration \\
\hline \multirow{2}{*}{$\begin{array}{l}\text { Non-linear } \\
\text { Analysis }\end{array}$} & $\begin{array}{l}\mathrm{R}-0 \\
\text { Model }\end{array}$ & max=-17.61 TINE=2.15 & $\left.{ }_{-600}^{600}\right]$ \\
\hline & $\begin{array}{l}\text { Bi-linear } \\
\text { Model }\end{array}$ & 20 & $\left.{ }_{-600}^{600}\right]$ - \\
\hline \multirow{3}{*}{$\begin{array}{l}\text { Equivalent } \\
\text { Linear } \\
\text { Analysis }\end{array}$} & $\begin{array}{l}\text { Resonant } \\
\text { Amplitude }\end{array}$ & $\max =-8.95$ TITE=1.93 & ${ }_{-600}^{600}=1$ max=509.67 TIFE=1.84 \\
\hline & $\begin{array}{l}\text { Dynanic } \\
\text { Stiffness }\end{array}$ & 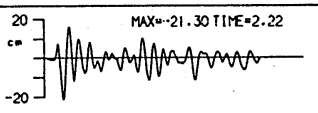 & 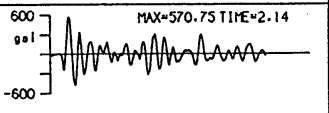 \\
\hline & $\begin{array}{l}\text { Geometrical } \\
\text { Stiffness }\end{array}$ & $\underset{0}{T_{10}^{20}} \underbrace{20}_{\text {TIE (SEC) }}$ & 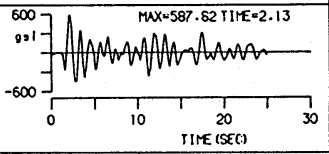 \\
\hline \multicolumn{2}{|c|}{ Input thave } & \multicolumn{2}{|c|}{ 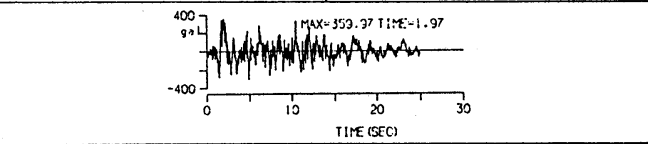 } \\
\hline
\end{tabular}

Fig. -7 Response Waves by Non-linear and Equivalent Linear Analysis (Level-2)

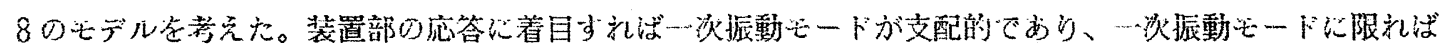

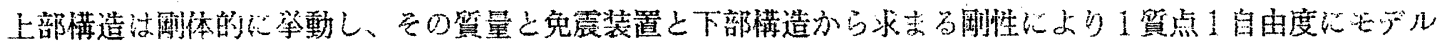

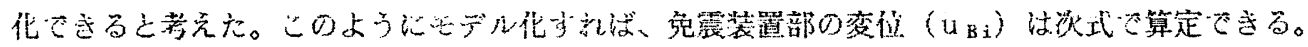




$$
\begin{aligned}
& \mathrm{U}_{\mathrm{B} i}=\mathrm{F}_{\mathbf{i}} / \mathrm{K}_{\mathrm{Bi}} \\
& \text { ここに、 } \quad \mathrm{F}_{\mathrm{i}} \text { : 各橋脚が分担与る慣性力 }\left(=\mathrm{k}_{\mathrm{h}} \cdot \mathrm{W} \cdot \mathrm{K}_{\mathrm{i}} / \sum \mathrm{K}_{\mathrm{i}}\right) \\
& \mathrm{k}_{\mathrm{h}} \text { : 固有周期、減衰を考虑した設計水平震度 } \\
& W: \text { 上部構造の重量 } \\
& \sum \mathrm{K}_{\mathrm{i}} \text { : 免震橋梁の等䧈羍性 }\left(1 / \mathrm{K}_{\mathrm{i}}=1 / \mathrm{K}_{\mathrm{B}_{\mathrm{i}}}+\mathrm{i} / \mathrm{K}_{\mathrm{Pi}}\right) \\
& \mathrm{K}_{\mathrm{B} i}, \mathrm{~K}_{\mathrm{Pi}} \text { : 免震装置、下部構造の胭性 }
\end{aligned}
$$

\section{7. 試計算によるもデル化の祫討}

图一1の憍梁を対家に、6.で提案した Menshin として表一1のスパイラル銅棒多シパー を想定し、レベル2入うでの最大応答值 を繰り返し計算により求方た。計算は図

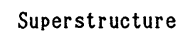

Superstructure

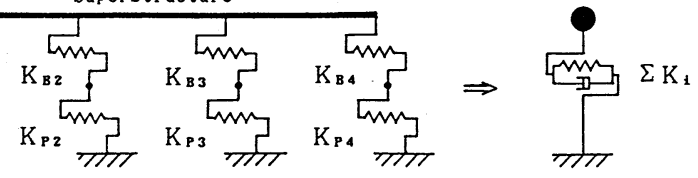

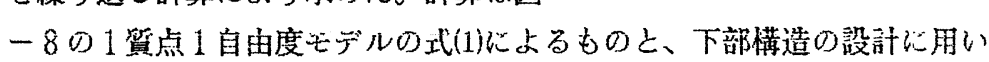
る方法、少なわ憍全体を図ー100骨組み洰デルに置換し、全体以慣性》 を静的に作用させ底答值を求める方法で行った。表一 4 以両で゙ルの度答

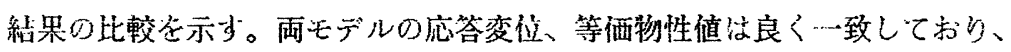
図ー8のモデル化が要当であることがわかる。この結果から、图ー8の1 貿点1自由度モデルによる繰り返し計算で、免震装置の特性值の設定、最

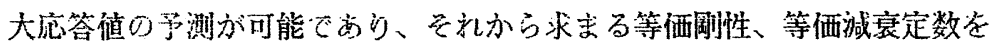

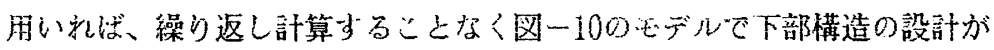

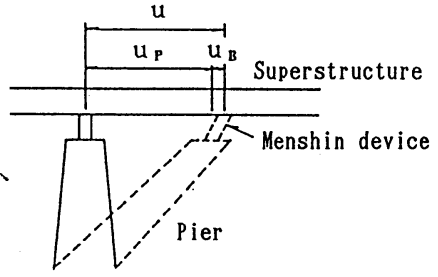

Fig. -9 Superstructure and Menshin Device Displacements 可能に斿方与考光ら礼る。

\section{8. まとめ}

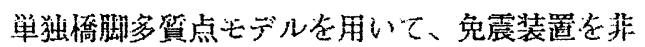
線形にたデル化した場合之等洒楾形化した場合の 地震应答解析結果炎比較し、等晒線形モデルが設

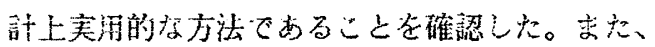
等価楾形化手法估、Dynamic Stiffness法、Geometrical Stiffness 法のいずれか走用いるのが 適当でるるとがわかった。免震装置の特性值を 設定する場合は、繰り返し計算するこ上等前提之 する。免震琶置部の応答を精度良く予测できる橋 梁モデルとして、下部構造と免震装置の等洒测性 から求まるバネと、上部構造の貿量から污る1筫

\begin{tabular}{|c|c|c|c|c|c|c|}
\hline \multirow[b]{2}{*}{ Model } & \multicolumn{4}{|c|}{$\begin{array}{l}\text { Menshin Device } \\
\text { Displacement }(\mathrm{cm})\end{array}$} & \multirow{2}{*}{$\begin{array}{l}\text { Equivalent } \\
\text { Natural } \\
\text { Period } \\
T_{. q}(\sec )\end{array}$} & \multirow{2}{*}{$\begin{array}{l}\text { Equivalent } \\
\text { Damping } \\
\text { Constant } \\
\mathrm{h}_{\mathrm{eq}}(\%)\end{array}$} \\
\hline & $A_{1}$ & $P_{1}$ & $\mathrm{P}_{2}$ & $\mathrm{~A}_{2}$ & & \\
\hline $\begin{array}{l}\text { Static Single Degree } \\
\text { of Freedom Model(Fig. }-8)\end{array}$ & 15.6 & 13.3 & 12.9 & 15.3 & 1.095 & 11.9 \\
\hline $\begin{array}{l}\text { Static Frane Model } \\
\text { (Fig. }-10)\end{array}$ & 16.4 & 13.0 & 12.3 & 15.8 & 1.075 & 12.0 \\
\hline
\end{tabular}
点1自由度モデルを提案した。

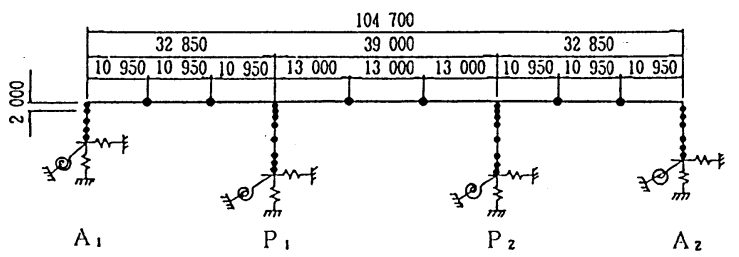

Fig.-10 Multi Degree of Freedom Model of Menshin Bridge

Table-4 Comparison of Maximum Menshin Device Displacement

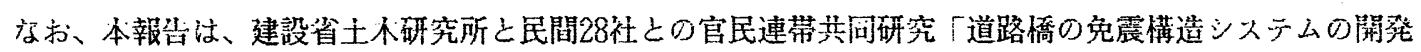
以関子る研究」の一環しして行われたるのでるる。

\section{参考文献}

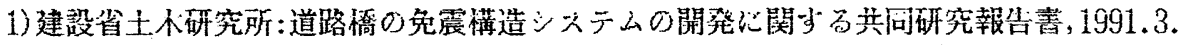

2) 忪尾・大石：宮川憍の設計之施工，憍梁之基礎, Vol.25, No.2, 1991.2.

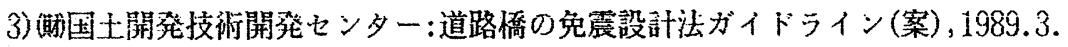

4) Jennings, P.C.:Equivalent Viscous Damping for Yielding Structures, Proc, ASCE, Vol.94, 1968.2. 